\title{
A comparison study on membrane fouling in a sponge-submerged
}

\section{membrane bioreactor and a conventional membrane bioreactor}

Lijuan Deng ${ }^{\mathrm{a}}$, Wenshan Guo ${ }^{\mathrm{a}}$, Huu Hao Ngo ${ }^{\mathrm{a}^{*}}$, Jian Zhang ${ }^{\mathrm{b}}$, Shuang Liang ${ }^{\mathrm{b}}$, Siqing Xia ${ }^{\mathrm{c}}$, Zhiqiang Zhang ${ }^{\mathrm{c}}$, Jianxin $\mathrm{Li}^{\mathrm{d}}$

${ }^{a}$ Centre for Technology in Water and Wastewater, School of Civil and Environmental Engineering, University of Technology, Sydney, Broadway, NSW 2007, Australia

${ }^{\mathrm{b}}$ Shandong Key Laboratory of Water Pollution Control and Resource Reuse, School of Environmental Science and Engineering, Shandong University, Jinan 250100, China

${ }^{c}$ State Key Laboratory of Pollution Control and Resource Reuse, College of Environmental Science and Engineering, Tongji University, Shanghai 200092, China

${ }^{\mathrm{d}}$ State Key Laboratory of Hollow Fiber Membrane Materials and Processes, School of Materials Science and Engineering, Tianjin Polytechnic University, Tianjin 300387, P. R. China

*Corresponding author, Email: h.ngo@uts.edu.au; Tel: +61-2-95142745; Fax: +61-2-95142633

\begin{abstract}
This study compared membrane fouling in a sponge-submerged membrane bioreactor (SSMBR) and a conventional membrane bioreactor (CMBR) based on sludge properties when treating synthetic domestic wastewater. In the CMBR, soluble microbial products
\end{abstract}


membrane fouling in SSMBR were also attributed to larger particle size, higher zeta potential and relative hydrophobicity of sludge flocs.

Keywords: Submerged membrane bioreactor; Sponge; Attached growth; Membrane fouling; Cake layer

\section{Introduction}


membrane fouling after 70 days of operation as well as less backwash frequency. A chemical cleaning-in-place (CIP) was investigated by Wei et al. (2011) in a long-term operation of pilot-scale submerged MBR for municipal wastewater treatment. They reported that the chemical CIP, in both transmembrane pressure (TMP) controlling mode and time controlling mode, effectively removed the fouling in terms of membrane pore blockage and gel layer caused by colloids and soluble organic substances. Wu and He (2012) suggested that the low irreversible fouling was found in the cyclic aeration mode, which could be ascribed to the floc destruction and re-flocculation processes. During the short high aeration period, the preservation of the strong strength bonds within activated sludge flocs caused less release of soluble and colloidal material in the supernatant. The weak strength bonds damaged in the high aeration period could be recovered in the re-flocculation process in the low aeration period.

In addition, using biomass carriers (e.g. plastic media, powdered activated carbon (PAC), sponge) in MBR is an effective and promising method to control membrane fouling. Jin et al. (2013) suggested that biomass flocs were less easily broken up with addition of relatively light and large-sized suspended carriers (AnoxKaldnes, K1 carriers) in ceramic SMBR. Moreover, both extracellular polymer substances (EPS) and soluble microbial products (SMP) were lower in the SMBR with carriers than those in the SMBR without carriers. $\mathrm{Ng}$ et al. (2013) indicated that higher concentration of fresh PAC in the SMBR could provide better simultaneous adsorption, decomposition, and biodegradation effects for the reduction of fouling components in the supernatant of the mixed liquor such as EPS, fine colloids and planktonic cells. As an idea attached growth media, sponge has also exhibited excellent performance during biological treatment due 
to its advantages of high internal porosity and specific surface area, high stability to hydrolyses, light weight and low cost (Ngo et al., 2006). When employing in MBRs, it can act as a mobile carrier for active biomass, reduce cake layer formation on the membrane surface and retain microorganisms by incorporating both their attached growth and suspended growth (Ngo et al., 2008). Guo et al. (2008) investigated the effects of sponge addition on sustainable flux and membrane fouling. They found that compared to SMBR alone, the suspended sponge cubes in the sponge-submerged membrane bioreactor (SSMBR) with sponge volume fraction of $10 \%$ could significantly reduce the membrane fouling as well as improve sustainable flux by 2 times. Nguyen et al. (2012) also confirmed that SSMBR had lower TMP development than that of conventional SMBR during primary effluent treatment. Meanwhile, SSMBR could maintain good microbial activity and constant sludge volume index value. 
The experiments were conducted using a synthetic wastewater to avoid any fluctuation in the feed concentration and provide a continuous source of biodegradable organic pollutants such as glucose, ammonium sulfate and potassium dihydrogen orthophosphate. It was used to simulate domestic wastewater just after primary treatment. The synthetic wastewater has dissolved organic carbon (DOC) of 100-130 $\mathrm{mg} / \mathrm{L}$, chemical oxygen demand (COD) of 330-360 mg/L, ammonium nitrogen $\left(\mathrm{NH}_{4}-\mathrm{N}\right)$ of $12-15 \mathrm{mg} / \mathrm{L}$ and orthophosphate $\left(\mathrm{PO}_{4}-\mathrm{P}\right)$ of $3.3-3.5 \mathrm{mg} / \mathrm{L}$. NaHCO ${ }_{3}$ or $\mathrm{H}_{2} \mathrm{SO}_{4}$ was used to adjust $\mathrm{pH}$ to 7 .

\subsection{Experimental setup and operating conditions}

A SSMBR and a CMBR with the same effective working volume were operated in parallel to compare the performance and membrane fouling behavior. For each MBR, a polyvinylidene fluoride (PVDF) hollow fiber module with a pore size of $0.2 \mu \mathrm{m}$ and surface area of $0.1 \mathrm{~m}^{2}$ was used. Both MBRs were filled with sludge from a local Wastewater Treatment Plant and acclimatized to synthetic wastewater. They were started with identical seeding activated sludge with similar initial sludge concentration (7.03 g/L for SSMBR, $6.98 \mathrm{~g} / \mathrm{L}$ for CMBR). No sludge was withdrawn from both MBRs. The reticulated porous polyester-polyurethane sponge (PUS) was used in 
using a feeding pump to control the feed rate while the effluent flow rate was controlled by a suction pump. A pressure gauge was used to measure the TMP and a soaker hose 


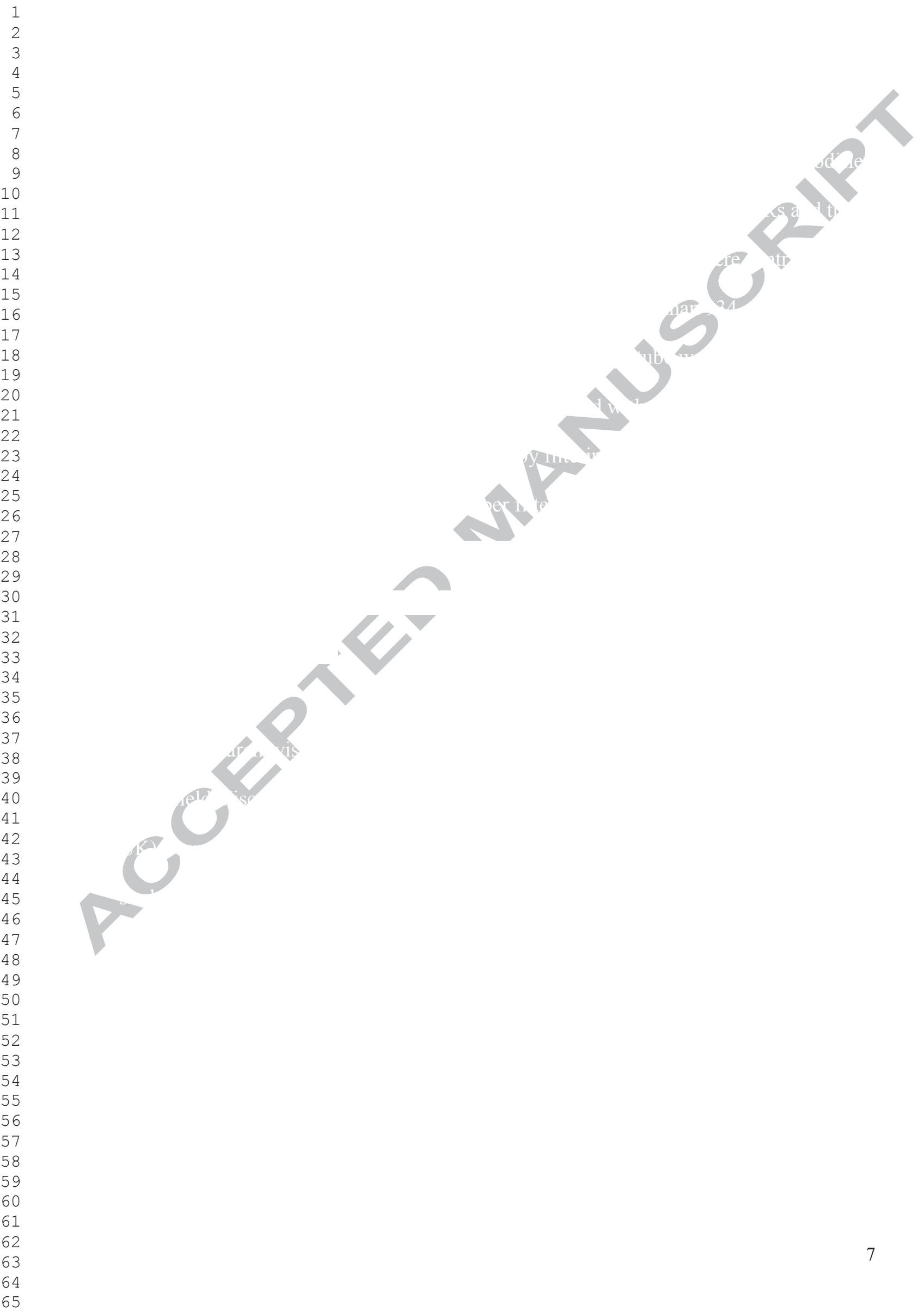


images of sludge particles obtained by the Olympus System Microscope Model BX41 
These results indicated that sponge addition could significantly mitigate membrane fouling, which is further discussed in details in Section 3.5.

Fig. 1.

\subsection{Mixed liquor suspended solids (MLSS) concentration and apparent viscosity}

During the experimental period, sludge concentration kept increasing in both MBRs due to no sludge withdrawal. MLSS concentrations were $11.50 \pm 4.52 \mathrm{~g} / \mathrm{L}$ and $9.41 \pm$ $2.38 \mathrm{~g} / \mathrm{L}$ in the CMBR and SSMBR after 35 and 90 days of operation, respectively. The lower MLSS concentration in the SSMBR might be attributed to the fact that sponge addition could balance the microorganism growth in suspended activated sludge as well as on and inside the porous sponge cubes (Ngo et al., 2006). It was found that there is an exponential relationship between MLSS concentration and sludge viscosity (Reid et al., 2008). In this study, sludge viscosity was higher $(3.30 \pm 0.50 \mathrm{mPa} \cdot \mathrm{s})$ in the CMBR than that $(2.60 \pm 0.40 \mathrm{mPa} \cdot \mathrm{s})$ in the $\mathrm{SSMBR}$, demonstrating that higher sludge viscosity was attributed to higher MLSS concentration. In addition, it has been reported that the sludge flocs with excess filamentous bacteria showed high viscosity due to presence of high EPS concentration (Meng et al., 2006a). Overgrowth of filamentous bacteria was found in the CMBR on day 14 , whereas there were less filamentous bacteria in the SSMBR until 83 days, which revealed that higher sludge viscosity in the CMBR was also due to abundance of filamentous bacteria. Similar observations were also recorded by Meng et al. (2007) who suggested that sludge viscosity was influenced by MLSS concentration, EPS and filamentous bacteria.

\subsection{Zeta potential, relative hydrophobicity $(R H)$ and particle size distribution}


It has been demonstrated that the flocculation ability of sludge flocs is affected by their hydrophobicity and surface charge, which positively influences the hydrophobic interaction and electrostatic repulsion, respectively (Liao et al., 2001; Mikkelsen and Keiding, 2002). In this study, activated sludge in the SSMBR had higher zeta potential $(-6.85 \pm 3.65 \mathrm{mV})$ and higher RH $(81.00 \pm 7.80 \%)$ than those in the CMBR (zeta potential of $-10.50 \pm 4.50 \mathrm{mV}$, RH of $63.13 \pm 13.60 \%$ ). The results indicated that there might be a positive relationship between surface charge (zeta potential) and hydrophobicity of activated sludge. Additionally, Meng et al. (2006a) reported that excess filamentous bacteria could prevent the agglomeration of floc particles by producing a bridge lattice due to the generation of abundant filaments from the flocs 
similar bound EPS concentrations, slightly higher protein concentrations $\left(\mathrm{EPS}_{\mathrm{P}}\right)$ but significantly lower polysaccharide concentrations $\left(\mathrm{EPS}_{\mathrm{C}}\right)$ were obtained in the CMBR. After 7 days of operation, the SMP concentrations (including $\mathrm{SMP}_{\mathrm{P}}$ and $\mathrm{SMP}_{\mathrm{C}}$ ) of both MBRs presented minor difference. On the other hand, bound EPS concentrations (12.3-24.6 mg/L) in the CMBR were higher than those in the SSMBR $(12.2-17.3$ $\mathrm{mg} / \mathrm{L})$, with lower protein concentrations $\left(\mathrm{EPS}_{\mathrm{P}}\right)$ but significantly higher polysaccharide concentrations $\left(\mathrm{EPS}_{\mathrm{C}}\right)$. In this study, increase of sludge concentration under infinite SRT condition induced the decrease in food to microorganism $(F / M)$ ratio $\left(0.1-0.2 \mathrm{~d}^{-1}\right)$. As a consequence, both MBRs were fed with limited available substrate, which could cause more cell lysis and cell hydrolysis, thereby releasing EPS and SMP in activated sludge (Yigit et al., 2008). Moreover, the excess growth of filamentous bacteria could produce more SMP, resulting in severe fouling (Pan et al., 2010). Therefore, the CMBR exhibited more serious fouling compared with the SSMBR. In the SSMBR, it was obvious that sponge addition could reduce $\mathrm{SMP}_{\mathrm{C}}$ concentrations during the first 7-day run and $\mathrm{EPS}_{\mathrm{C}}$ afterwards by the means of adsorption onto sponge as well as biodegradation by attached biomass of the sponge.

It has been reported that large quantity of EPS in activated sludge increased floc strength by polymer entanglement, thereby increasing the extent of sludge flocs agglomeration (Mikkelsen and Keiding, 2002). However, in this study, lower EPS concentration but larger particles were observed in the SSMBR, pointing out that the flocculation ability of sludge flocs may not only depend on EPS concentration. Lee et al. (2003) found that the ratio of proteins to polysaccharides (PN/PS ratio) in EPS was important in controlling the hydrophobicity and surface charge of sludge flocs. Table 3 
shows that a significantly higher PN/PS ratio in bound EPS was found in the SSMBR after 7 days operation. Higher RH of activated sludge in the SSMBR proved that higher EPS $_{P}$ concentration increased the hydrophobicity of sludge flocs by providing amino acids with more hydrophobic side groups, while lower $\mathrm{EPS}_{\mathrm{C}}$ concentration contributed to less hydrophilic nature of sludge. Moreover, the amino groups in $\mathrm{EPS}_{\mathrm{P}}$ containing positive charges neutralized some of negatively charged activated sludge, thereby inducing higher zeta potential of sludge flocs in the SSMBR (Lee et al., 2003; Liao et al., 2001). Thus, PN/PS ratio in bound EPS could positively influence hydrophobicity and zeta potential of activated sludge, thereby having an impact on the agglomeration ability of the flocs.

Table 2.

Table 3.

\subsection{Membrane fouling behaviour}

Results of fouling resistance showed that the CMBR had a higher total resistance $\left(\mathrm{R}_{\mathrm{T}}\right)\left(5.47 \times 10^{12} \mathrm{~m}^{-1}\right)$ than that of the SSMBR $\left(2.56 \times 10^{12} \mathrm{~m}^{-1}\right)$. The clean membrane resistance $\left(R_{M}\right)$ were the same $\left(1.71 \times 10^{12} \mathrm{~m}^{-1}\right)$ for both MBRs. Higher cake layer resistance $\left(\mathrm{R}_{\mathrm{C}}\right)$ was found for the CMBR than that for the SSMBR, corresponding to $3.04 \times 10^{12} \mathrm{~m}^{-1}$ and $0.85 \times 10^{12} \mathrm{~m}^{-1}$, respectively. Moreover, pore blocking resistance $\left(R_{P}\right)$ for the CMBR was notably higher. $R_{P}$ of the CMBR accounted for about $20 \%$ of $R_{T}$, whereas there was no $R_{P}$ in the SSMBR. These results suggested that cake layer formation was one of the main factors contributing to membrane fouling. Furthermore, sponge could alleviate membrane fouling not only by preventing pore blocking but also by reducing cake layer formation. Some researchers (Jamal Khan et al., 2012; Yang et 
al., 2006) have reported the similar findings that $\mathrm{R}_{\mathrm{C}}$ was major fraction of $\mathrm{R}_{\mathrm{T}}$ and sponge addition could reduce $\mathrm{R}_{\mathrm{C}}$.

As discussed in Section 3.2, activated sludge in both MBRs possessed different properties, which were correlated with membrane fouling potential as well as fouling resistance. Higher MLSS concentration could lead to formation of a sticky cake layer on membrane surface due to higher sludge viscosity (Itonaga et al., 2004). Additionally, the sludge flocs with abundance of filamentous bacteria would more easily deposit on membrane surface due to its high viscosity, causing the formation of a non-porous cake layer (Meng et al., 2006a). Therefore, it could be noted that higher MLSS concentration and overgrowth of filamentous bacteria contributed to formation of sticky and nonporous cake layer, giving rise to higher $\mathrm{R}_{\mathrm{C}}$ in the CMBR. Being the major fraction of the total fouling resistance, the cake layer was analysed with respect to EPS and SMP (including polysaccharides and proteins). Fig. 2 shows the composition of EPS and SMP in the cake layer on membrane surface for both SSMBR and CMBR. Bound EPS concentrations were similar for the SSMBR $(15.0 \mathrm{mg} /(\mathrm{L} \cdot \mathrm{g}$ cake layer $))$ and the CMBR (13.9 $\mathrm{mg} /\left(\mathrm{L} \cdot \mathrm{g}\right.$ cake layer)). However, higher concentrations of $\mathrm{SMP}_{\mathrm{C}}$ and $\mathrm{SMP}_{\mathrm{P}}(14.4$ and $15.5 \mathrm{mg} /\left(\mathrm{L} \cdot \mathrm{g}\right.$ cake layer), respectively) were obtained for the CMBR, while $\mathrm{SMP}_{\mathrm{C}}$ and $\mathrm{SMP}_{\mathrm{P}}$ of the cake layer were comparatively lower for the SSMBR (9.8 and 7.1 $\mathrm{mg} /\left(\mathrm{L} \cdot \mathrm{g}\right.$ cake layer), respectively). These results elucidated that higher $\mathrm{R}_{\mathrm{C}}$ in the $\mathrm{CMBR}$ was mainly caused by SMP (including $\mathrm{SMP}_{\mathrm{C}}$ and $\mathrm{SMP}_{\mathrm{P}}$ ) on membrane surface. At high TMP, more $\mathrm{SMP}_{\mathrm{C}}$ and $\mathrm{SMP}_{\mathrm{P}}$ could be adsorbed and/or attached onto membrane surface due to the high drag force provided by permeate pump. On contrary, sponge addition effectively reduced $\mathrm{SMP}_{\mathrm{C}}$ and $\mathrm{SMP}_{\mathrm{P}}$ in cake layer on membrane surface. Apart from 
adsorption of $\mathrm{SMP}_{\mathrm{C}}$ and $\mathrm{SMP}_{\mathrm{P}}$ on the sponge and biodegradation by attached microorganisms, reduction of cake layer could be also attributed to physical clearance mechanism of sponge, such as frictional force exerted by circulating media on submerged membrane, solute back-transport effect from the membrane surface to the bulk solution due to turbulence of suspended carriers, and membrane shaking by the impact of suspended carriers against them (Lee et al., 2006; Yang et al., 2006).

Fig. 2.

Since particles could lead to severe membrane fouling by pore blocking and cake formation on the membrane (Lim and Bai, 2003), the CMBR contained smaller sludge flocs and induced higher TMP increment rate (Fig. 1), which illustrated that the presence of smaller sludge flocs contributed to higher $R_{C}$ and $R_{P}$ in the CMBR. As larger particles could not easily deposit on membrane surface due to higher shear induced diffusion and inertial lift force, SSMBR demonstrated significantly lower membrane fouling propensity (Pan et al., 2010).

In addition, as above-mentioned in Section 3.4, SMP in activated sludge appeared as a major contribution to initial membrane fouling. However, in later stage, membrane fouling development was mainly governed by bound EPS in activated sludge. It has been showed that SMP could increase fouling tendency due to the combined effects of pore clogging and adsorption on membrane walls and within membrane pores (Shen et al., 2012). Thus, higher SMP content of the CMBR cake layer led to higher $\mathrm{R}_{\mathrm{P}}$, which was well consistent with the results by Jamal Khan et al. (2012). Besides, higher concentration of bound EPS in activated sludge could also increase both $R_{C}$ and $R_{P}$ in 
the CMBR. Ng et al. (2006) observed a thick fouling layer on the membrane consisting of microbial cells covered with EPS, which blocked membrane pores. Similar results were also found by Meng et al. (2006b) that the total amount of EPS had a significant positive correlation with the fouling resistance caused by pore blocking and cake formation.

Previous studies have reported that PN/PS ratio in EPS or SMP had a significant impact on filtration resistance as well as fouling propensity (Lee et al., 2003; Tian et al., 2011; Yao et al., 2011). In this study, as both SMP and EPS (especially $\mathrm{SMP}_{\mathrm{C}}$ and $\mathrm{EPS}_{\mathrm{C}}$ ) were responsible for membrane fouling in the CMBR, a new fouling indicator 
the CMBR governed membrane fouling in the initial stage and later stage, respectively. However, sponge addition could mitigate membrane fouling significantly by preventing pore blocking and reducing cake layer formation. In the SSMBR, lower $R_{C}$ and $R_{P}$ were ascribed to lower biomass growth, lower sludge viscosity, less filamentous bacteria, larger sludge flocs, as well as lower concentrations of SMP and bound EPS in activated sludge.

\section{Acknowledgements}

The authors sincerely thank the support of UTS, Centre for Technology in Water and Wastewater, Research Theme: Sustainable Water: Wastewater treatment and Reuse Technologies and Management; 1st World Membrane Bioreactor (MBR) Centre; and the joint University of Technology Sydney-China Scholarship Council (UTS-CSC) Doctor of Philosophy (PhD) Scholarship.

\section{References}

1. APHA, AWWA, and WEF, 1998. Standard Methods for the Examination of Water and Wastewater, twentieth ed. American Public Health Association, Washington, DC.

2. Choo, K.H., Lee, C.H., 1996. Membrane fouling mechanisms in the membrane coupled anaerobic bioreactor. Water Research 30, 1771-1780.

3. Frølund, B., Palmgren, R., Keiding, K., Nielsen, P.H., 1996. Extraction of extracellular polymers from activated sludge using a cation exchange resin. Water Research 30, 1749-1758. 
4. Guo, W.S., Ngo, H.H., Vigneswaran, S., Xing, W., Goteti, P., 2008. A novel sponge submerged membrane bioreactor (SSMBR) for wastewater treatment and reuse. Separation Science and Technology 43, 273-285.

5. Guo, W.S., Ngo, H.H., Palmer, C.G., Xing, W., Hu, A.Y.J., Listowski, A., 2009. Roles of sponge sizes and membrane types in a single stage sponge-submerged membrane bioreactor for improving nutrient removal from wastewater for reuse. Desalination 249, 672-676.

6. Guo, W.S., Ngo, H.H., Li, J.X., 2012. A mini-review on membrane fouling. Bioresource Technology 122, 27-34.

7. Itonaga, T., Kimura, K. Watanabe, Y., 2004. Influence of suspension viscosity and colloidal particles on permeability of membrane used in membrane bioreactor (MBR). Water Science and Technology 50, 301-309.

8. Jamal Khan, S., Zohaib-Ur-Rehman, Visvanathan, C., Jegatheesan, V., 2012. Influence of biofilm carriers on membrane fouling propensity in moving biofilm membrane bioreactor. Bioresource Technology 113, 161-164.

9. Ji, J., Qiu, J., Wai, N., Wong, F.S., Li, Y., 2010. Influence of organic and inorganic flocculants on physical-chemical properties of biomass and membrane-fouling rate. Water Research 44, 1627-1635.

10. Jin, L., Ong, S.L., Ng, H.Y., 2013. Fouling control mechanism by suspended biofilm carriers addition in submerged ceramic membrane bioreactors. Journal of Membrane Science 427, 250-258.

11. Kimura, K., Hane, Y., Watanabe, Y., Amy, G., Ohkuma, N., 2004. Irreversible membrane fouling during ultrafiltration of surface water. Water Research 38, $3431-3441$. 
12. Lee, W., Kang, S., Shin, H., 2003. Sludge characteristics and their contribution to microfiltration in submerged membrane bioreactors. Journal of Membrane Science $216,217-227$.

13. Lee, W.N., Kang, I.J., Lee, C.H., 2006. Factors affecting filtration characteristics in membrane-coupled moving bed biofilm reactor. Water Research 40, 1827-1835.

14. Liao, B.Q., Allen, D.G., Droppo, I.G., Leppard, G.G., Liss, S.N., 2001. Surface properties of sludge and their role in bioflocculation and settleability. Water Research 35, 339-350.

15. Lim, A.L., Bai, R., 2003. Membrane fouling and cleaning in microfiltration of activated sludge wastewater. Journal of Membrane Science 216, 279-290.

16. Meng, F., Zhang, H., Yang, F., Li, Y., Xiao, J., Zhang, X., 2006a. Effect of filamentous bacteria on membrane fouling in submerged membrane bioreactor. Journal of Membrane Science 272, 161-168.

17. Meng, F., Zhang, H., Yang, F., Zhang, S., Li, Y., Zhang, X., 2006b. Identification of activated sludge properties affecting membrane fouling in submerged membrane bioreactors. Separation and Purification Technology 51, 95-103.

18. Meng, F., Shi, B., Yang, F., Zhang, H., 2007. Effect of hydraulic retention time on membrane fouling and biomass characteristics in submerged membrane bioreactors. Bioprocess and Biosystems Engineering 30, 359-367.

19. Meng, F., Drews, A., Mehrez, R., Iversen, V., Ernst, M., Yang, F., Jekel, M., Kraume, M., 2009. Occurrence, source, and fate of dissolved organic matter (DOM) in a pilot-scale membrane bioreactor. Environmental Science and Technology 43, $8821-8826$. 
20. Mikkelsen, L.H., Keiding, K., 2002. Physico-chemical characteristics of full scale sewage sludges with implications to dewatering. Water Research 36, 2451-2462.

21. Ng, H.Y., Tan, T.W., Ong, S.L., 2006. Membrane fouling of submerged membrane bioreactors: impact of mean cell residence time and the contributing factors.

Environmental Science and Technology 40, 2706-2713.

22. Ng, C.A., Sun, D., Bashir, M.J.K., Wai, S.H., Wong, L.Y., Nisar, H., Wu, B., Fane, A.G., 2013. Optimization of membrane bioreactors by the addition of powdered activated carbon. Bioresource Technology 138, 38-47.

23. Ngo, H.H., Nguyen, M.C., Sangvikar, N.G., Hoang, T.T.L., Guo, W.S., 2006. Simple approaches towards the design of an attached-growth sponge bioreactor (AGSB) for wastewater treatment and reuse. Water Science and Technology 54, 191-197.

24. Ngo, H.H., Guo, W.S., Xing, W., 2008. Evaluation of a novel sponge-submerged membrane bioreactor (SSMBR) for sustainable water reclamation. Bioresource Technology 99,2429-2435.

25. Ngo, H.H., Guo, W.S., 2009. Membrane fouling control and enhanced phosphorus removal in an aerated submerged membrane bioreactor using modified green bioflocculant. Bioresource Technology 100, 4289-4291.

26. Nguyen, T.T., Ngo, H.H., Guo, W.S., Li, J.X., Listowski, A., 2012. Effects of sludge concentrations and different sponge configurations on the performance of a sponge-submerged membrane bioreactor. Applied Biochemistry and Biotechnology $167,1678-1687$. 
27. Pan, J.R., Su, Y.C., Huang, C., Lee, H.C., 2010. Effect of sludge characteristics on membrane fouling in membrane bioreactors. Journal of Membrane Science 349, 287-294.

28. Reid, E., Liu, X., Judd, S.J., 2008. Sludge characteristics and membrane fouling in full-scale submerged membrane bioreactors. Desalination 219, 240-249.

29. Shen, Y.X., Xiao, K., Liang, P., Sun, J.Y., Sai, S.J., Huang, X., 2012.

Characterization of soluble microbial products in 10 large-scale membrane bioreactors for municipal wastewater treatment in China. Journal of Membrane Science 415-416, 336-345.

30. Tian, Y., Chen, L., Zhang, S., Cao, C., Zhang, S., 2011. Correlating membrane fouling with sludge characteristics in membrane bioreactors: An especial interest in EPS and sludge morphology analysis. Bioresource Technology 102, 8820-8827.

31. Wei, C.H., Huang, X., Aim, R.B., Yamamoto, K., Amy, G., 2011. Critical flux and chemical cleaning-in-place during the long-term operation of a pilot-scale submerged membrane bioreactor for municipal wastewater treatment. Water Research 45, 863-871.

32. Wu, J., He, C., 2012. Effect of cyclic aeration on fouling in submerged membrane bioreactor for wastewater treatment. Water Research 46, 3507-3515.

33. Yang, Q.Y., Chen, J.H., Zhang, F., 2006. Membrane fouling control in a submerged membrane bioreactor with porous, flexible suspended carriers. Desalination 189, 292-302.

34. Yao, M., Ladewig, B., Zhang, K., 2011. Identification of the change of soluble microbial products on membrane fouling in membrane bioreactor (MBR). Desalination 278, 126-131. 
35. Yigit, N.O., Harman, I., Civelekoglu, G., Koseoglu, H., Cicek, N., Kitis, M., 2008. Membrane fouling in a pilot-scale submerged membrane bioreactor operated under various conditions. Desalination 231, 124-132. 
Table Titles

Table 1 Removal efficiency of DOC, COD, $\mathrm{PO}_{4}-\mathrm{P}, \mathrm{NH}_{4}-\mathrm{N}$ and TN in SSMBR and CMBR during the operation period.

Table 2 SMP compositions and total SMP concentrations of mixed liquor in SSM $\mathbb{R}$ and CMBR at two different stages (within and after 7 days of operation) duri the operation period.

Table 3 Bound EPS compositions and total bound EPS concentro no mixed liquor in SSMBR and CMBR at two different stages (within and afto 7 trays of operation) during the operation period.

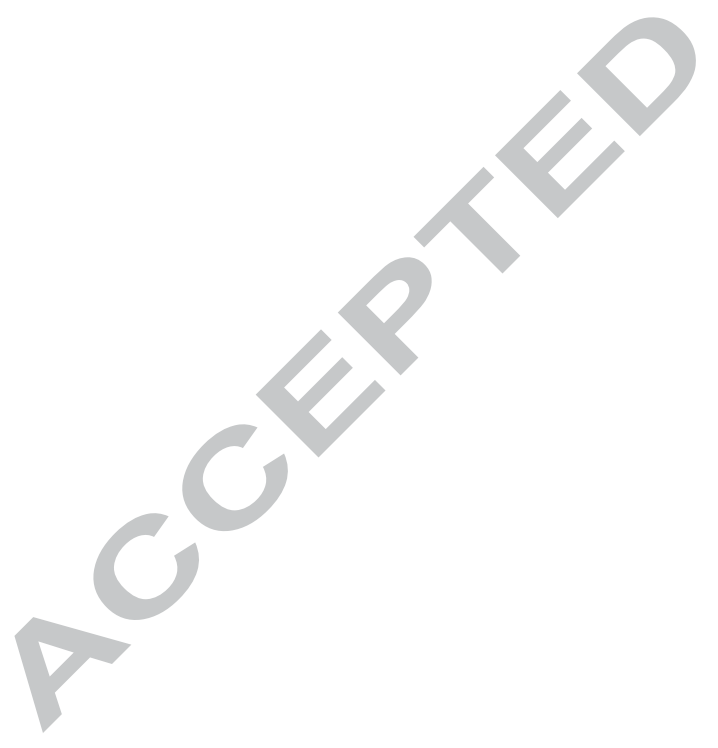


Table 1

Removal efficiency of DOC, COD, $\mathrm{PO}_{4}-\mathrm{P}, \mathrm{NH}_{4}-\mathrm{N}$ and $\mathrm{TN}$ in SSMBR and CMBR during the operation period.

\begin{tabular}{cccccc}
\hline Reactors & DOC $(\%)$ & $\mathrm{COD}(\%)$ & $\mathrm{PO}_{4}-\mathrm{P}(\%)$ & $\mathrm{NH}_{4}-\mathrm{N}(\%)$ & $\mathrm{TN}(\%)$ \\
\hline SSMBR & $94.74 \pm 5.49$ & $93.53 \pm 4.46$ & $63.57 \pm 5.32$ & $74.35 \pm 3.22$ & $53.28 \pm 2.16$ \\
CMBR & $94.17 \pm 7.32$ & $91.95 \pm 6.53$ & $27.22 \pm 6.18$ & $58.14 \pm 6.13$ & $37.20 \pm 4.58$ \\
\hline
\end{tabular}




\section{ACCEPTED MANUSCRIPT}

Table 2

SMP compositions and total SMP concentrations of mixed liquor in SSMBR and

CMBR at two different stages (within and after 7 days of operation) during the operation period.

\begin{tabular}{cccccc}
\hline \multirow{2}{*}{ Day } & \multirow{2}{*}{ Reactor } & \multicolumn{4}{c}{ SMP } \\
\cline { 3 - 6 } & & $\mathrm{PN}^{\mathrm{a}}(\mathrm{mg} / \mathrm{L})$ & $\mathrm{PS}^{\mathrm{b}}(\mathrm{mg} / \mathrm{L})$ & $\mathrm{PN} / \mathrm{PS}$ ratio & SMP $(\mathrm{mg} / \mathrm{L})$ \\
\hline Stage I & SSMBR & $9.9-10.2$ & $7.2-9.4$ & $1.1-1.4$ & $7.4-17.4$ \\
(Day 1-7) & CMBR & $10.6-10.8$ & $13.5-14.4$ & $0.7-0.8$ & $24.1-25.2$ \\
\hline Stage II & SSMBR & $1.0-4.4$ & $1.0-6.9$ & $0.3-2.3$ & $1.5-9.2$ \\
$($ After day 7) & CMBR & $0.4-5.7$ & $1.0-5.8$ & $0.1-3.2$ & $1.1-9.8$ \\
\hline
\end{tabular}

${ }^{\mathrm{a}} \mathrm{PN}$, proteins; ${ }^{\mathrm{b}} \mathrm{PS}$, polysaccharides 


\section{ACCEPTED MANUSCRIPT}

Table 3

Bound EPS compositions and total bound EPS concentrations of mixed liquor in

SSMBR and CMBR at two different stages (within and after 7 days of operation) during the operation period.

\begin{tabular}{lccccc}
\hline \multirow{2}{*}{ Day } & \multirow{2}{*}{ Reactor } & \multicolumn{4}{c}{ Bound EPS } \\
\cline { 3 - 6 } & & $\mathrm{PN}^{\mathrm{a}}(\mathrm{mg} / \mathrm{L})$ & $\mathrm{PS}^{\mathrm{b}}(\mathrm{mg} / \mathrm{L})$ & $\mathrm{PN} / \mathrm{PS}$ ratio & Total EPS (mg/L) \\
\hline \multirow{2}{*}{ Stage I } & SSMBR & $7.4-9.9$ & $9.4-11.8$ & $0.6-1.1$ & $19.2-19.3$ \\
(Day 1-7) & CMBR & $9.3-9.9$ & $1.0-9.4$ & $4.7-9.3$ & $10.3-19.3$ \\
\hline Stage II & SSMBR & $9.8-10.6$ & $1.6-7.5$ & $1.3-6.6$ & $12.2-17.3$ \\
(After Day 7) & CMBR & $6.5-10.1$ & $5.8-14.5$ & $0.7-1.4$ & $12.3-24.6$ \\
\hline
\end{tabular}

${ }^{\mathrm{a}} \mathrm{PN}$, proteins; ${ }^{\mathrm{b}} \mathrm{PS}$, polysaccharides 


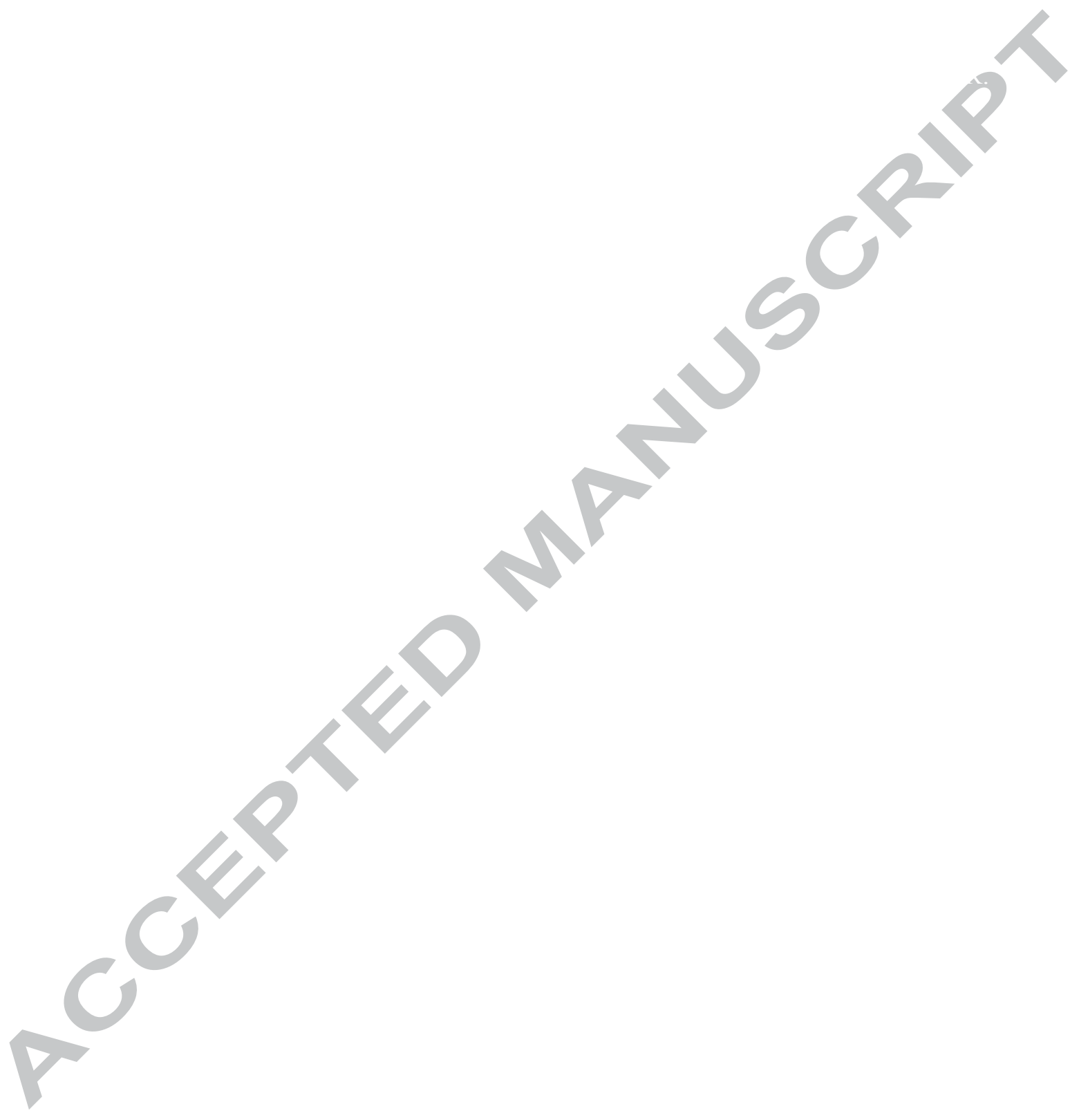




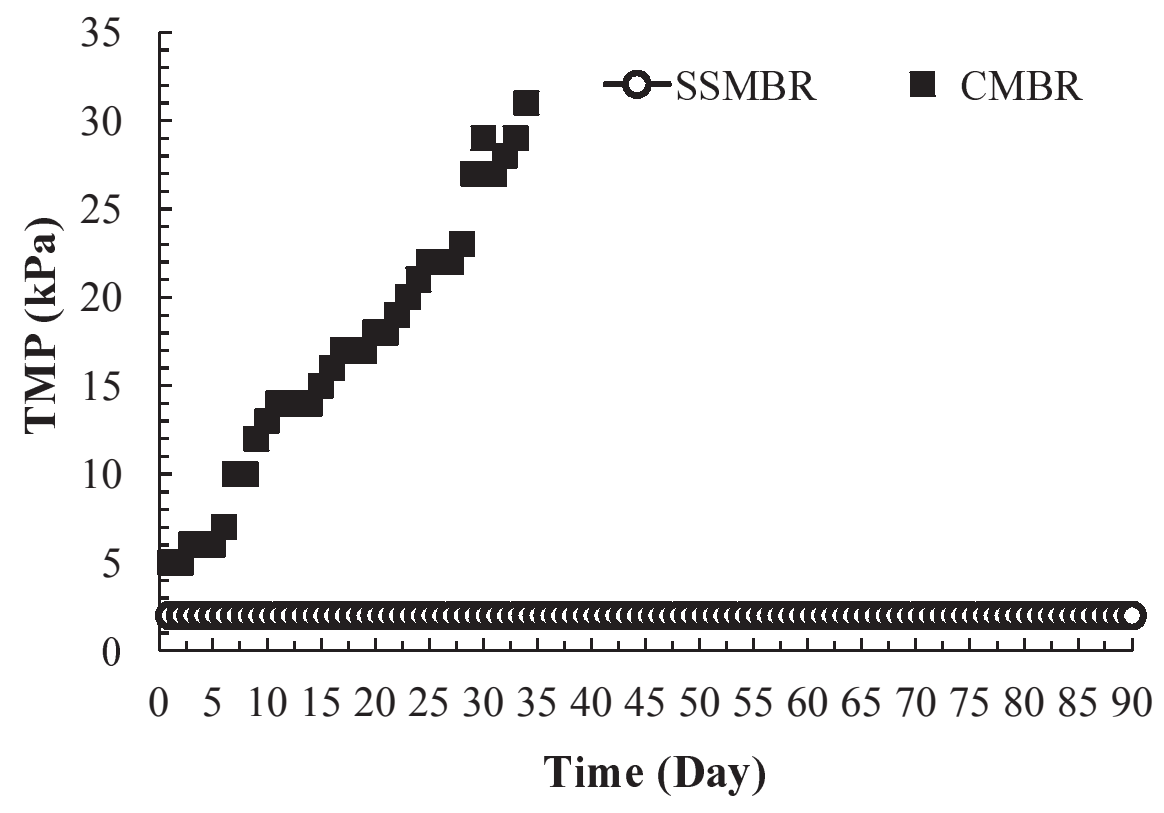

Fig. 1. 


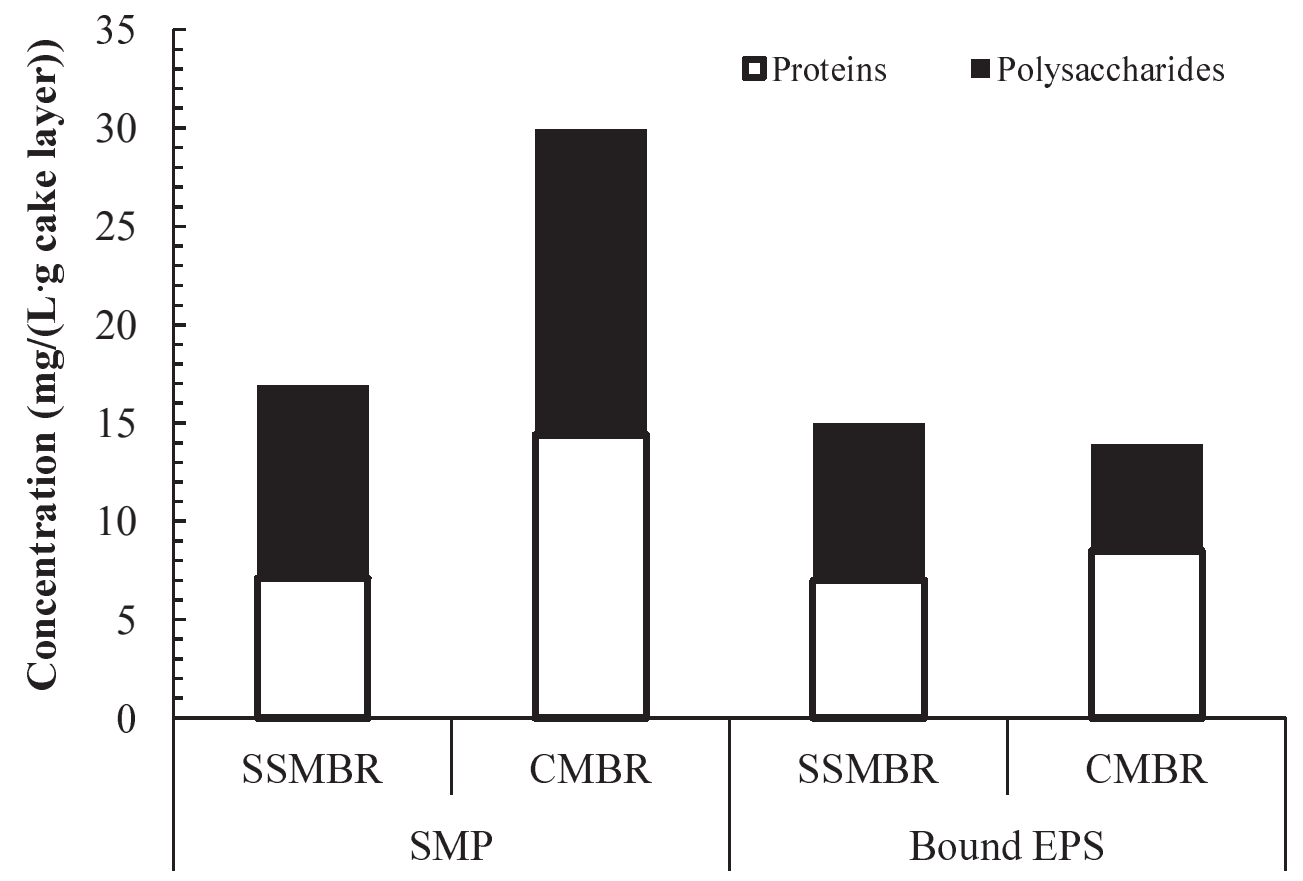

Fig. 2. 


\section{Highlights}

- Less SMP and bound EPS in activated sludge in the SSMBR induced lower $\mathrm{R}_{\mathrm{C}}$ and $\mathrm{R}_{\mathrm{P}}$.

- Lower biomass growth and sludge viscosity contributed to lower $\mathrm{R}_{\mathrm{C}}$ in the $\mathrm{S}$ M. $\mathrm{R}$.

- Larger sludge flocs, higher zeta potential and RH led to lower $\mathrm{R}_{\mathrm{T}}$ in the SMBR.

- Sponge could prevent pore blocking and cake layer formatio

- Sponge addition could reduce $\mathrm{SMP}_{\mathrm{C}}$ and $\mathrm{EPS}$, rough adsorption and biodegradation.

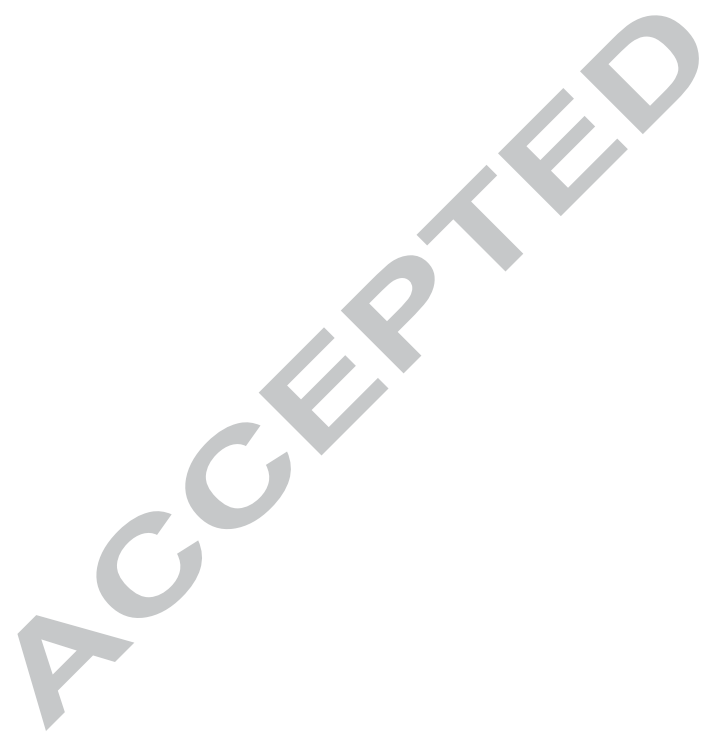

